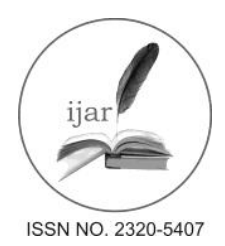

Journal homepage: http://www.journalijar.com

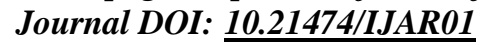

INTERNATIONAL JOURNAL

OF ADVANCED RESEARCH

RESEARCH ARTICLE

\title{
URETERAL TRIPLICATION WITH STRICTURE OF MIDDLE URETER AND ECTOPIC INSERTION
} OF URETER.

\section{Vohra Aditi ${ }^{1}$, Ranjan Kumar ${ }^{2}$, Narula Harneet ${ }^{3}$.}

1. MD, Associate Prof, Dept of Radiodiagnosis and Imaging- M.M. Institute of Medical Sciences and Research, Mullana,(Distt-Ambala),Haryana, India.

2. Post graduate (PG), Dept of Radiodiagnosis and Imaging- M.M. Institute of Medical Sciences and Research, Mullana,(Distt-Ambala),Haryana, India.

3. MD, DNB Associate Prof, Dept of Radiodiagnosis - M.M. Institute of Medical Sciences and Research, Mullana,(Distt-Ambala),Haryana, India.

\section{Manuscript Info}

Manuscript History:

Received: 18 March 2016

Final Accepted: 19 April 2016

Published Online: May 2016

Key words:

ureter, triplication, stricture.

*Corresponding Author

Vohra Aditi.

\begin{abstract}
Ureteral triplication is a rare congenital anomaly of urinary tract with wide spectrum of presentation. The association of ureteral triplication with stricture of one of the branch is very rare and has hardly been reported in literature. We present a case of 20 year old boy presenting with recurrent urinary tract infection and with occasional haematuria. Ultrasonography revealed hydroureter with likely double moiety and ectopic insertion of ureter into the prostatic urethra. On CT urography, triple moiety of the right kidney was revealed with stricture of middle ureter at site of union of ureters and resultant proximal hydroureter. Renal tissue was dysplastic in mid pole. Ectopic insertion of single ureter into the prostatic urethra was also seen. Radiological features along with embryology and review of literature is discussed.
\end{abstract}

Copy Right, IJAR, 2016,. All rights reserved.

\section{Introduction:-}

Ureteral triplication is one of the rarest malformation of upper urinary tract. Ureteral triplication is a rare congenital anomaly which was first described by Wrany in $1870 .{ }^{1}$ A review of the literature showed that there have been only few hundred reported cases of this condition. It is more common in females. Association with other urological anomalies has been reported. ${ }^{2}$ But association with stricture of one of the ureteric branch is very rare and has not been reported to our best knowledge. The following case report discusses a patient with triple moiety of kidney with stricture of middle ureter at site of union with other ureters and ectopic insertion of single ureter into the prostatic urethra.

\section{Case report:-}

A 20 year old boy presented with recurrent urinary tract infection with few episodes of hematuria. Physical examination was unremarkable. Routine blood examinations revealed normal peripheral blood count, serum urea, and creatinine level. Urine examinations revealed the presence of urinary infection.

Special investigations done included ultrasonography (USG) and MDCT urography (MDCTU). Ultrasonography showed both the kidneys to be of normal size and cortical thickness with normal corticomedullary differentiation. Hydroureter was revealed on right side with likely double moiety. The right ureter appeared as dilated and tubular structure and was ectopically inserted into the prostatic urethra. 
MDCT urogram was performed on Ingenuity CT (128 slice, Philips Medical System). Unenhanced CT images were acquired through the abdomen from level of kidneys to pelvic brim and did not demonstrate any renal stones. $\mathrm{i} / \mathrm{v}$ contrast was given and scanning was performed 80 seconds after injection (for nephrographic phase). Scan was then repeated at 10 minutes after injection (for excretory phase). It revealed triple moiety of the right kidney with three separate ureters. Ureters united in mid portion at level of iliac vessels. Middle ureter was grossly dilated with severe smooth narrowing seen at site of union s/o stricture. (Figure 1)
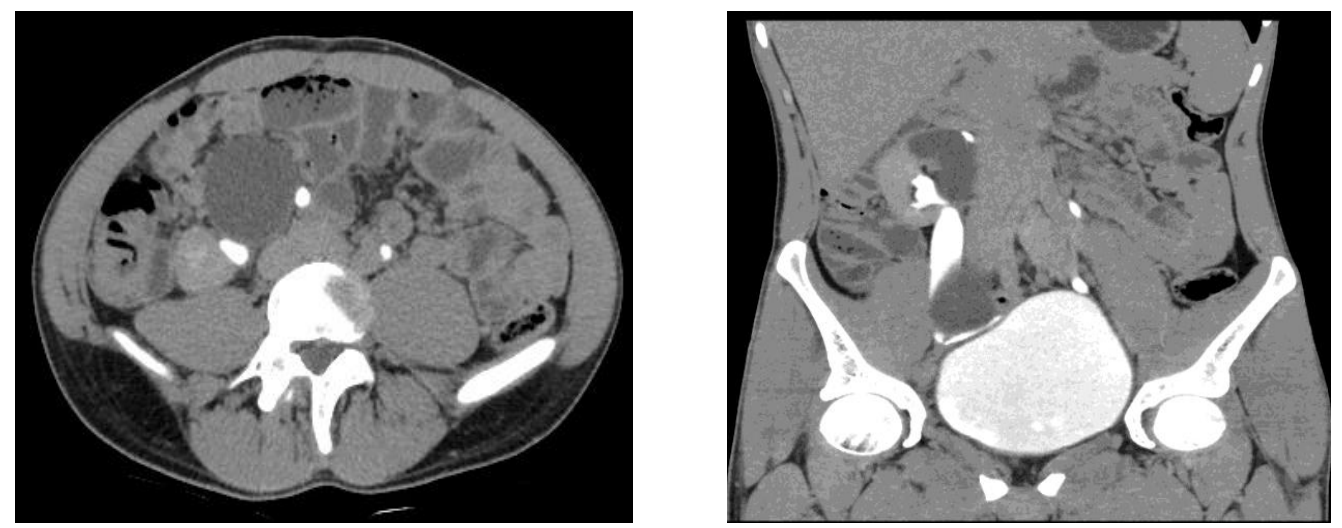

Figure 1:- Axial CT urogram (1a) and Coronal reformation (1b) shows triplication of ureter with union of ureters at midlevel. Stricture of middle ureter is seen at level of union.

There was gross proximal dilatation of ureter. (Figure 2)
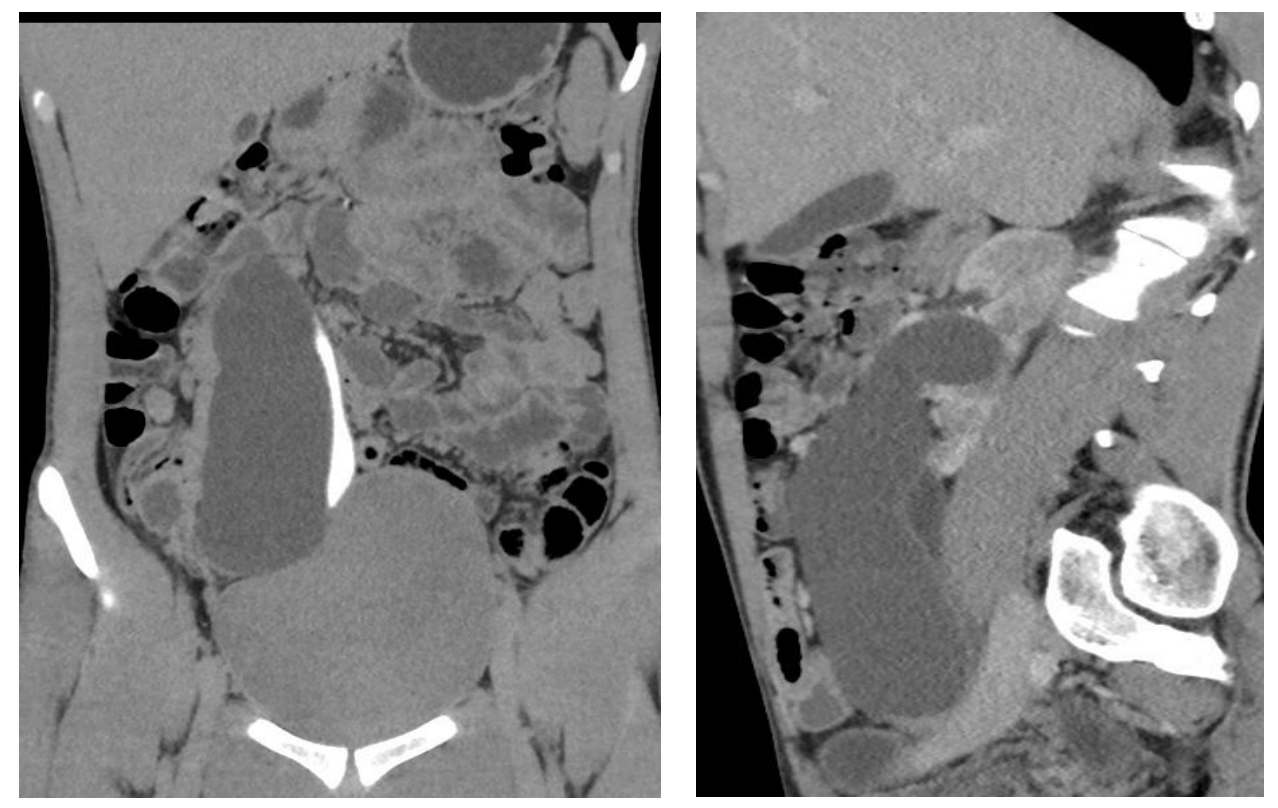

Figure 2:- Coronal (2a) and sagittal (2b) CT reformatted images shows grossly dilated middle ureter.

Mid pole of kidney appeared dysplastic with hypertrophy of upper and lower poles. There was normal excretion in upper and lower moiety ureters but no contrast excretion was seen in middle ureter.

In addition, there was ectopic insertion of single ureter into the prostatic urethra. There was narrowing at site of insertion of ureter into prostatic urethra with proximal dilatation of single ureter. (Figure 3, 4)

Segmental vertebral anomalies was also seen in the patient. 

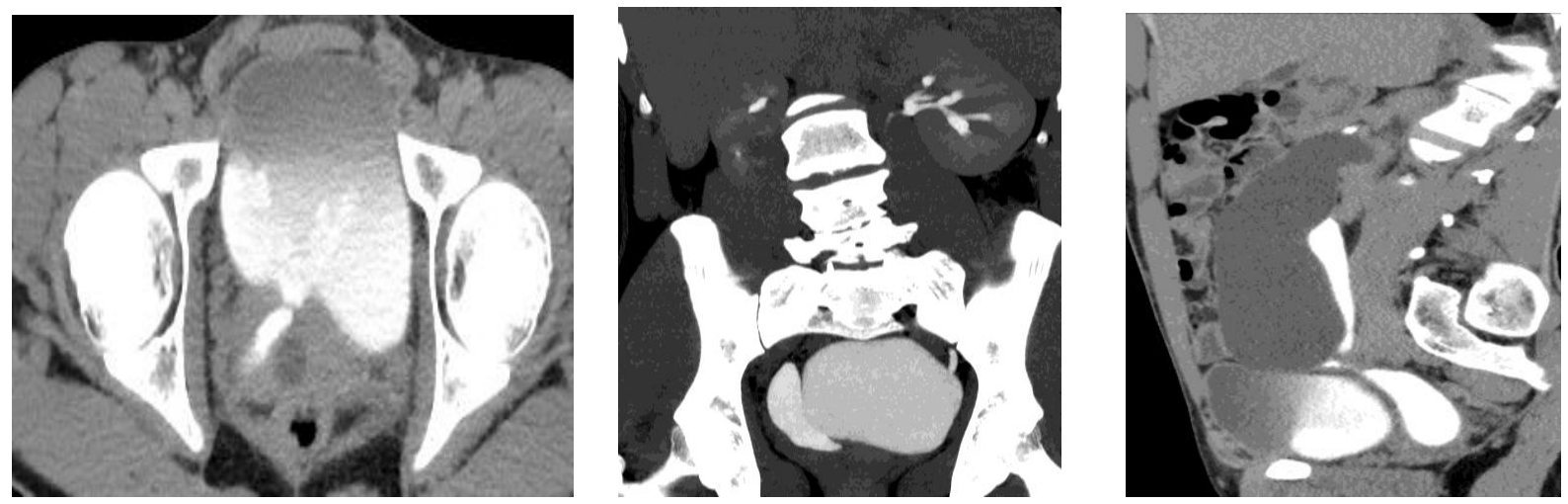

Figure 3:- Axial section of CT urogram (3a) shows ectopic insertion of single ureter into prostatic urethra. Coronal (3b) and sagittal $(3 \mathrm{c})$ reformation shows dilated lower $1 / 3^{\text {rd }}$ of ureter.
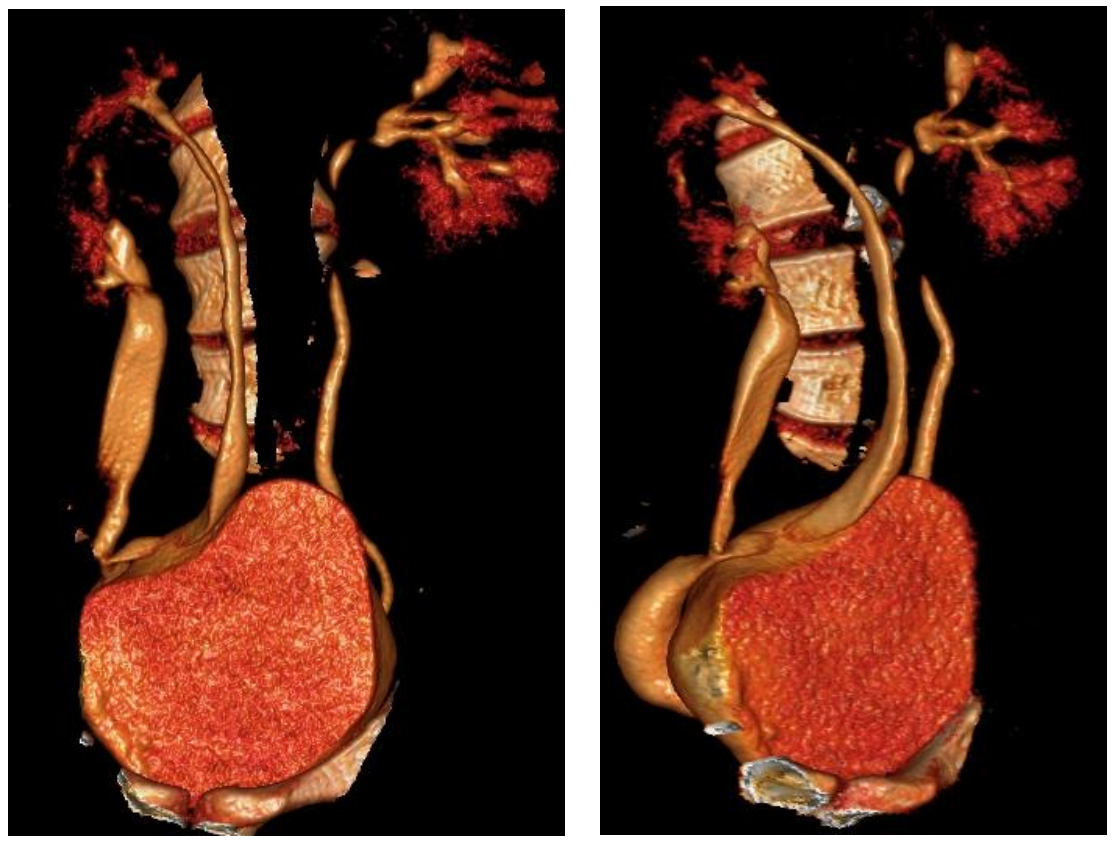

Figure 4:- 3D reformatted images (4a and b) shows upper and lower moiety of right kidney with separate pelvicalyceal system with union of ureters at mid portion. Mid pole of kidney was dysplastic with no obvious calyces visualized. Middle ureter is not visualized as there was no contrast excretion in it. Figure $4 \mathrm{~b}$ shows dilated single ureter after the level of union.

\section{Discussion:-}

Ureteral triplication is an extremely uncommon congenital urinary anomaly, with only few hundred cases reported worldwide. Presentation is often delayed due to paucity of symptoms and signs. The most common presentations are recurrent urinary infection and enuresis. ${ }^{3}$ Enuresis occurs in the case of a female child with ectopic ureteric orifice.

Smith classified ureteral triplication into four types ${ }^{4}$ -

Type 1: complete ureteral triplication (35\%); three separate ureters from the kidney with three separate draining orifices to bladder or elsewhere in urinary tract. 
Type 2: Incomplete triplication (21\%); three ureters arise from kidney but two of these join draining into two ureteric orifices.

Type 3: Trifid ureter (31\%); all three ureters join together before reaching the bladder and drain through a single orifice.

Type 4: Double ureter one of them bifurcated (9\%); two ureters arise from the kidney, one becoming an inverse Y bifurcation, draining into three orifices.

Our case is subtype of type- 3 of smith classification.

Ureteral triplication is developmental abnormality of ureteral bud originating from wolffian duct. Distal part of wolffian duct gives rise to ureteral bud duct. It grows dorsally and cranially to make contact with metanephros. Distal end differentiates into renal pelvis and major and minor calyces. In triplication of ureter, three ureteral buds arise from mesonephric duct or a result of early fissuring of one or more ureteral buds while joining metanephros. ${ }^{5}$

Unlike the duplex systems, the positions of ureteral orifices in complete triplication of ureter do not always follow the "Weigert-Meyer rule." ${ }^{, 6}$ This rule states that the ureteral orifice of upper pole moiety inserts into the bladder medial and inferior to both its normal location and orifice of the ureter draining the lower renal segment. ${ }^{7}$ In these cases, the ureter draining the upper pole moiety frequently ends in a ureterocele where as reflux occurs into the lower moiety. This principle does not apply uniformly in ureteral triplication. Out of the 13 patients with ureteral triplication studied by Mark R. Zaontz this was true only in seven. ${ }^{8}$ Perkins et al described eight patients with Type1 ureteral triplication; out of them, five patients did not conform to the Weigert-Meyer law. ${ }^{9}$

Triplication of ureter can be associated with other urological anomalies like contralateral duplication, ureteral ectopia, renal dysplasia, reflux and ureterocele. ${ }^{10,11}$ Rarely blind ending branch of ureter can be associated. This anomaly usually result from failure of premature branch of ureteric bud to joint with metanephric blastema. ${ }^{12}$ Association with stricture of one of the branch has not been reported to our best knowledge.

In our case, there was stricture of middle ureter at site of union with other ureters with gross proximal hydroureter. Renal tissue in mid pole of kidney was dysplastic with poor differentiation of cortex and medulla. No calyceal dilatation was seen in mid pole.

In addition, there was ectopic insertion of ureter into prostatic urethra in our case. Ectopic insertion of ureter stems from abnormal ureteral bud migration and usually results in caudal ectopia. Normally, the primitive ureteral bud travels cephalad, where as the wolffian duct from which it originates travels caudad. However if the ureteral bud fails to separate from the wolffian duct, it may be carried into more caudal position than normal. Consequently, the opening of the ureter becomes caudally ectopic. ${ }^{13}$ In the female, it may insert into lower bladder, urethra, vestibule, or vagina. So in females, it may result into incontinence. In males, it empties into lower bladder, posterior urethra, seminal vesicle, vas deferens or ejaculatory duct. ${ }^{14}$ In our case, ureter opened into the posterior urethra.

Our case was unique because association of triplication of ureter with stricture of one of the branch is a very rare presentation. This case emphasizes the importance of diagnosis with complete evaluation of urinary tract which can guide the urologist in management of patients with recurrent urinary tract infections.

\section{Conclusion:-}

Ureteral triplication associated with stricture of one of branch is a very rare congenital anomaly of urinary tract which has not been reported in literature to our best knowledge.MDCT is one of the best modality to diagnose ureteral abnormalities and is crucial for diagnosis and pre-operative planning. 


\section{References:-}

1. Li J, Hu T, Wan M, Chen S, et al.Ureteral triplication: The first report in China. J Pediatr Sung 2004;39:E38-9.

2. Alhajri F, Al-Jumah A, Al-Mutawa S.Ureteral triplication with a contralateral duplication and ureterocele: a case report. Cases J.2009;2:7510.

3. Zivkovic D, Varga J, Grebeldinger S, Borisev V. Ureteral triplication-a case report. Med Pregl.2005;58:592-5.

4. Smith I. Triplicate Ureter. Br J Surg 1946;34:182-5.

5. Kirtikumar J R, Dhananjay V, Prakash KR, Lakshmi NK. Urteral triplication:need to seen beyond the splitting of the ureteral bud. Annals of Pediatric Surg 2012;8:95-98.

6. Lugue-Mialdea R, De TE, Arrojo F, et al. Ureteral triplication: Double extravesical ureteral ectopia. J Urol 1991;145:109-11.

7. Fernbach SK, Feinstein KA, Spencer K,Lindstrom CA. Ureteral Duplication and its Complications. Radiographics 1997;17:109-127.

8. Zaontz MR, Maizels M. Type I Ureteral triplication: An extension of the Weigert-Meyer, law. J Urol 1985;134:949-50.

9. Perkins PJ, Kroovand LR, Evans AT. Radiology 1973;108:533.

10. Sivrikaya A, Cay A, Imamoglu M, Sarihan H. A case of ureteral triplication associated with uretero-pelvic junction obstruction. IntUrolNephrol 2007;39:755-57.

11. Kokabi N, Price N, Smith GHH, Holland AJ. Ureteral triplication: A rare anomaly with a variety of presentations. Journal of pediatric urology 2011;7:484-7.

12. Chang E, Santillan C, O’Boyle MK. Blind-ending branch of a bifid ureter: multi detector CT imaging findings. Br J Radiol 2011;84:e038-40.

13. Berrocal T, Lopez-Pereira P, Arjonilla A, Gutierrez F. Anomalies of the Distal Ureter, Bladder and Urethra in Children: Embryologic, Radiologic and Pathological Features. Radiographics 2002;22:1139-64.

14. Engelstein D, Livne PM, Cohen M, Servadio C. Type II ureteral triplication associated with ectopic ureter. Urology 1996;48:786-8. 